\title{
Aluminum Based Composites Obtained by FSP (Review)
}

\author{
Christo Kondoff \\ IMSETCH ”Acad. A Balevski” - \\ Bulgarian Academy of Sciences \\ Sofia, Bulgaria \\ hriko61@gmail.com
}

\author{
Radostina Zaekova \\ IMSETCH ”Acad. A Balevski” - \\ Bulgarian Academy of Sciences \\ Sofia, Bulgaria \\ rzaekova@mail.bg
}

\author{
Marina Manilova \\ IMSETCH ”Acad. A Balevski” - \\ Bulgarian Academy of Sciences \\ Sofia, Bulgaria \\ mamanil@abv.bg
}

\begin{abstract}
The composites based on aluminum alloys obtained by friction stir processing (FSP) combine the advantages of lightweight aluminum composites with the well-refined structure obtained by deformation in plastic state. When reinforcing elements in the form of powders or nanoplates are introduced in the process, of mixing they are evenly distributed in the processes zone, which acquires a fine-grained structure. The study examines specific results in
\end{abstract}

\section{INTRODUCTION}

The composite materials, called "composites" for brevity, have a complex of useful qualities and are widely used nowadays. In most cases the application of metal matrix composites (MMC), and in particular aluminum matrix composites (AMC), is limited due to their high cost despite their high performance combined with low weight [1]. Extremely good opportunities for creating composites are provided by the technology for friction stir processing (FSP) [2], [3] and the technology friction stir welding (FSW) for in non-detachable joining.

Both processes FSW and FSP, as the former is developed by TWI Cambridge, UK [4] in 1991 and the latter is developed by Mishra, India [2] in year 2000, are based on the same principles. The main parameters of the process, which determine the properties of the processed layer, are the applied load, tool rotation velocity, traverse velocity of processing, and tool type and geometry. The process FSP has acquired worldwide spread due to the following advantages [5] - [7]:

- $\quad$ Can be realized on universal metalworking machines and machining centers;

- No expensive consumables, additive materials or gasses, etc. are required; the use of various tools and materials, as well as some basic parameters of the process in terms of surface smoothness, defects and some performance characteristics of the tested samples, such as strength, ductility, hardness and corrosion resistance.

Keywords - aluminum alloys composites, friction stir processing (FSP), fine-grained structure, nanoplates

- $\quad$ No specialized power source is required;

- The temperatures are lower than those for conventional overlay welding and the alloying elements are preserved;

- The material is not melted but only plasticized, so there is no distortion and stability of the geometric dimensions is ensured;

- Allows surface processing of dissimilar materials;

- The costs for pre-cleaning and sanding after processing are reduced;

- Allows to process a specific area of the surface;

- The process is clean and protects the environment and human health;

- Refinement of the microstructure due to the intensive mixing. The results achieved after FSP are grain refinement, breaking the nonmetallic inclusions and the coarse dendritic structure, and occurrence of dynamic recrystallization, characterized by a large number of high-angle grain boundaries [6]. 
FSP is used as an excellent technique for making MMK with reinforcing or modifying powders introduced and uniformly dispersed in the processed area.

\section{GEOMETRY OF THE TOOLS FOR FSP}

The geometry of the tool is one of the most important factors in FSP, which plays a key role for stirring the material. The speed with which FSP is carried out depends on the tool geometry. The tool for FSP consists of shoulder and pin, as is shown in Fig. 1.

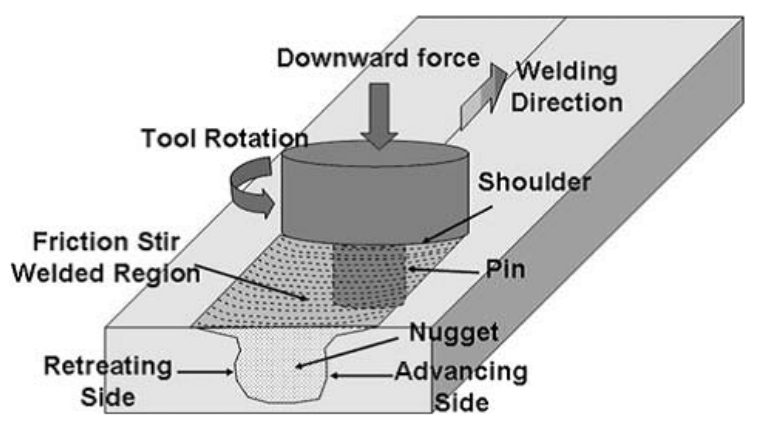

Fig. 1. Scheme of FSP [8].

The tool has two main functions: (a) local heating, and (b) stirring the material. On the initial stage of entering the tool, the heating is obtained mainly by the friction between the pin and the part. Additional heat is released as a result of the deformation of the material. The tool penetrates the material until the shoulder comes in contact with the top surface. The friction between the shoulder and the part leads to the release of a large amount of heat. From the point of view of the heat released, the relative size of the pin and the shoulder is important.

The second function of the tool is to "mix" and "move" the material. The uniformity of the microstructure and the properties, as well as the efforts in the process depend on the design of the tool. The most commonly used tool combines a concave shoulder with threaded cylindrical pins, see Fig. 2 [9].

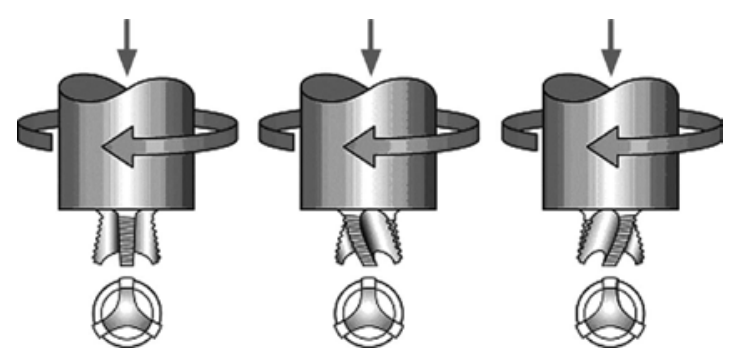

Fig. 2. Flared-Triflute TM tools developed by TWI, UK: (a) neutral flutes, (b) left flutes, and (c) right hand flutes (after Thomas et al.) [9].

The main factor determining the advantage of tools with threaded pins and flutes over the conventional cylindrical pins is the ratio of the entrained volume of the material during rotation to the volume of the pin itself, i.e. ratio between the "dynamic volume" and the "static volume", which is important to ensure adequate flow during mixing. Typically, this ratio for pins with similar root diameters and lengths is 1.1: 1 for conventional cylindrical pin, 1.8:1 for pin model WhorlTM, and 2.6:1 for pin model MX TrifluteTM (in welding plate with thickness $25 \mathrm{~mm})$ [9].

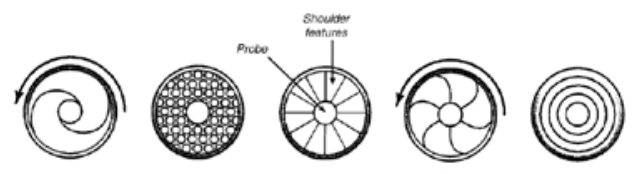

Fig. 3. Tool shoulder designs [10].

Different tool shoulder profiles are designed to suit different materials and conditions of processing, see Fig. 3. These shoulder profiles improve the quality of processing and ensure reintroduction of the plasticized material into the stirring zone.

The profile of the pin in Fig. 4 has a significant impact on hardness, strength and wear resistance [11].

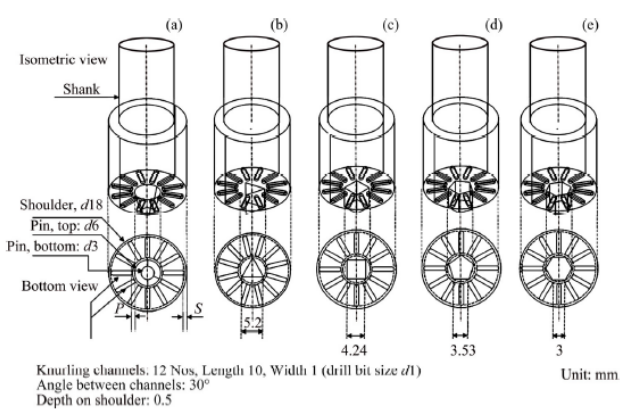

Fig. 4. Tools used in FSW process showing knurling shoulder feature [11]

As a result of the research performed regarding the type of instrument, the following conclusions can be made:

- Defects, such as delamination, tunnel defects and imperfections, are observed in the microstructures of the areas processed with the individual tools, which are probably due to the unstable flow of the plasticized material due to improper combination of geometry of the pin and the shoulder.

- The best results are observed with a tool having square pin and shoulder with knurling re-entrant channels, which ensures uniform distribution of the plasticized material, both on the advance side and the retreat side of the weld.

- The instrument with a square pin and a shoulder with knurling re-entrant channels also shows the best values for ultimate tensile strength of $182 \mathrm{MPa}$ and hardness of HV78. 
Environment. Technology. Resources. Rezekne, Latvia Proceedings of the $13^{\text {th }}$ International Scientific and Practical Conference. Volume 3, 148-153

TABLE 1 FORCE, TORQUE AND MECHANICAL PROERTIES OF WELDS WITH DIFFERENT TOOLS [11]

\begin{tabular}{|c|c|c|c|c|c|c|c|}
\hline $\begin{array}{c}\text { Sample } \\
\text { No. }\end{array}$ & Tool & $\begin{array}{c}\text { Number of } \\
\text { sides }(n)\end{array}$ & $\begin{array}{l}\text { Static to dynamic } \\
\text { volume ratio }\end{array}$ & $\begin{array}{c}\text { Axial } \\
\text { force' } / \mathrm{NN}\end{array}$ & $\begin{array}{c}\text { Tool torque"' } \\
(\mathrm{aN} \mathrm{m})\end{array}$ & $\begin{array}{l}\mathrm{UTS} / \\
\mathrm{MPa}\end{array}$ & $\begin{array}{l}\text { Avg micro-handthess } \\
\text { in stir zobe" (HV) }\end{array}$ \\
\hline 1 & $\begin{array}{l}\text { Taper cylindrical pin } \\
\text { shaped tood }\left(\mathrm{T}_{\mathrm{x}}\right)\end{array}$ & & 1 & 6.5 & 58.9 & $172 \pm 0.5$ & 70.2 \\
\hline 2 & $\begin{array}{c}\text { Triangular pin shaped } \\
\text { tool }\left(\mathrm{T}_{\mathrm{k}}\right)_{\mathrm{T}}\end{array}$ & 3 & 2.4 & 5.4 & 48.5 & $178+1.0$ & 62.1 \\
\hline 3 & $\begin{array}{l}\text { Square pin shiped } \\
\text { tool }\left(\mathrm{T}_{\mathrm{x}}\right) \mathrm{s}\end{array}$ & 4 & 1.57 & 60 & 54.0 & $182 \pm 0.8$ & 78.2 \\
\hline 4 & $\begin{array}{l}\text { Pentagonal pin shaped } \\
\text { tool }\left(\mathrm{T}_{\mathrm{k}}\right) \text { ? }\end{array}$ & 5 & 1.32 & 59 & 53.1 & $171 \pm 0.6$ & 80.6 \\
\hline 5 & $\begin{array}{l}\text { Hexagonal pin staped } \\
\text { tool }\left(\mathrm{T}_{\mathrm{X}}\right)_{\mathrm{y}}\end{array}$ & 6 & 1.2 & 6.4 & 56.7 & $172 \pm 1.2$ & 78.1 \\
\hline
\end{tabular}

Similar results are obtained in FSP of composites based on $\mathrm{Al}-\mathrm{Mg}$ alloy (4 wt\% $\mathrm{Mg}$ ) reinforced with $1 \mathrm{wt} \% \mathrm{SiC}$ and $1 w t \%$ graphite particles [12]. In addition to providing reliable joining, the FSP carried out significantly affects the mechanical properties of hardness, tensile strength and wear resistance. The reduction of the grain size, according to the mathematical dependence derived by Hall-Petch, gives information about the quantitative change of the mechanical characteristics. The heat released due to friction of a tool with a square-head pin is significantly less than that in case of hexagonal- or octagonal-head pins. The smaller grain growth in the stirring zone occurs in the process of cooling to room temperature. This means that the use of a tool with a square head pin provides enhanced mechanical properties.

Aluminum alloys of all series can be subjected to FSP. There are data for FSP of alloys of dissimilar composition. There are a number of techniques used to obtain AMCs using FSP, which are described below.

\section{OBTAINING AMC BY INCORPORATING REINFORCING PARTICLES INTO THE MATRIX THROUGH CHANNELS AND FURTHER FSP WITH A TOOL WITHOUT PIN OR A TOOL WITH TAPERED PIN [7].}

Fig. 5 [7] shows the scheme of FSP for obtaining AMC based on alloy AA 6061-T6 with different concentrations of reinforcing $\mathrm{Al} 2 \mathrm{O} 3$ particles.

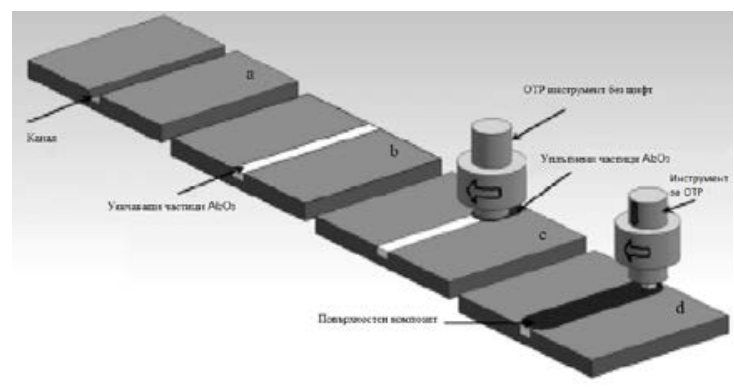

Fig. 5. Obtaining AMC through FSP [7].

The microstructures of nano composites obtained through different modes of FSP are shown in Fig. 6.

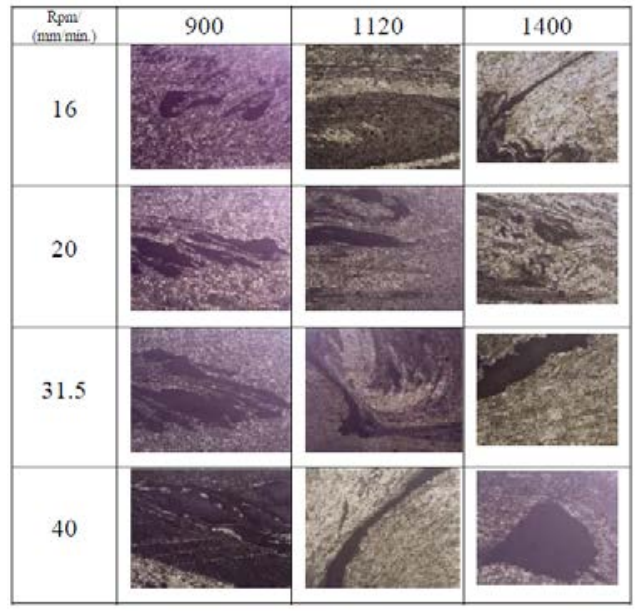

a)

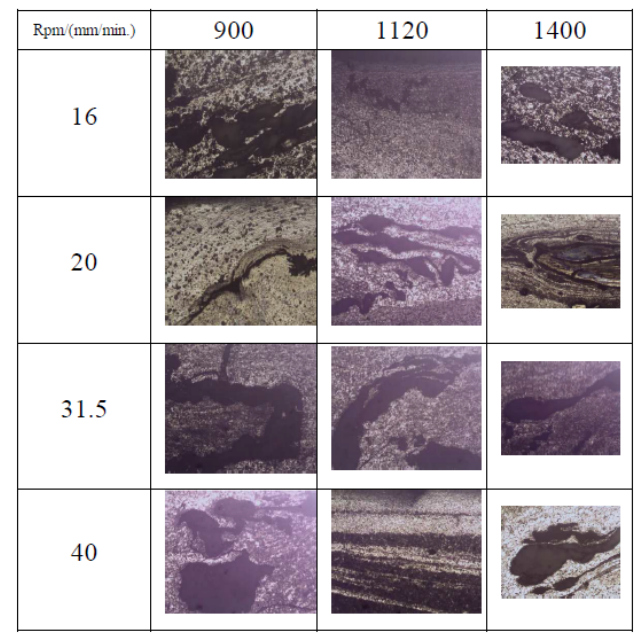

b)

Fig. 6. Microstructures of composites with concentration of nano particles (a) $2 \%$, and (b) $6 \%$ [7].

It was found that a defect-free structure was obtained at concentration 2 vol. \% of the reinforcing nano particles, tool rotation speed $1120 \mathrm{rpm}$, traverse speed $16 \mathrm{~mm} / \mathrm{min}$ and a threaded taper pin tool with concave shoulder. Fig. 7 displays the comparison between the hardness of composites with 2 vol. \% and 6 vol.\% nanoparticles with respect to the raw material.

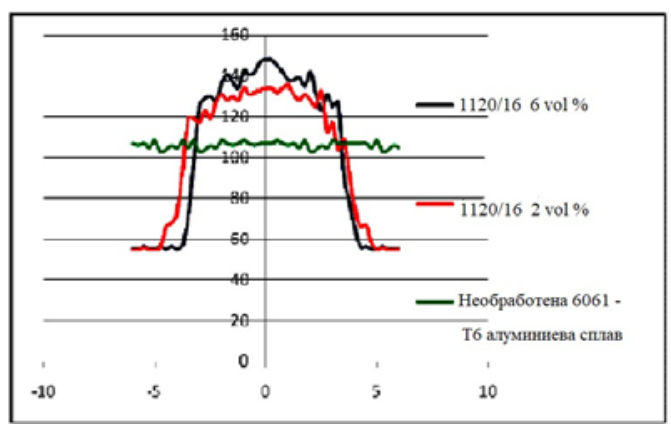

Fig. 7. Hardness of the composites [7]. 
It is obvious that at rotational speed $1120 \mathrm{rpm}$, traverse speed $16 \mathrm{~mm} / \mathrm{min}$, and $6 \mathrm{vol}$ \% concentration of $\mathrm{Al} 2 \mathrm{O} 3$ nano particles the hardness of the obtained composite reaches $132 \mathrm{HV}$.

\section{OBTAINING AMK BY INCORPORATING REINFORCING PARTICLES INTO THE MATRIX BY DRILLING CYLINDRICAL HOLES AND FURTHER FSP [13].}

AMK based on alloy 7075-T651 with reinforcing nanoparticles of SiC and ash in ratio 60:40, 75:25 and 90:10 and concentrations $4 \%, 8 \%$ and $12 \%$ volume percentages are obtained by FSP [13]. The processing is performed under the following parameters:

- $\quad$ Tool rotation speed 500, 1000 and 1500 rpm;

- Traverse speed 20, 30 and $40 \mathrm{~mm} / \mathrm{min}$.

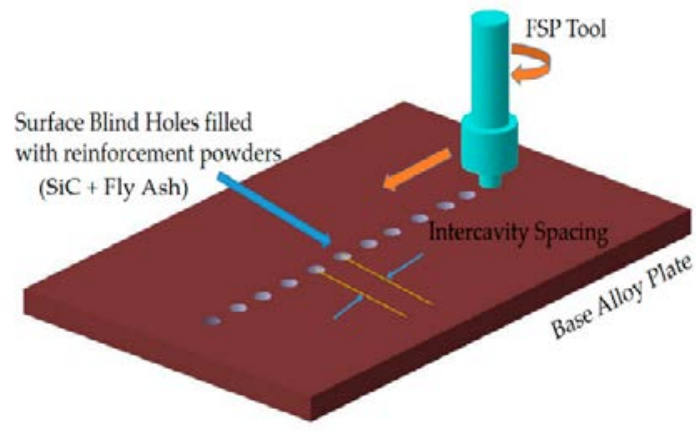

Fig. 8. FSP by introduction of the reinforcing powder in blind holes [13].

The influence of these parameters on the microstructure of composites, wear rate and microhardness is studied.

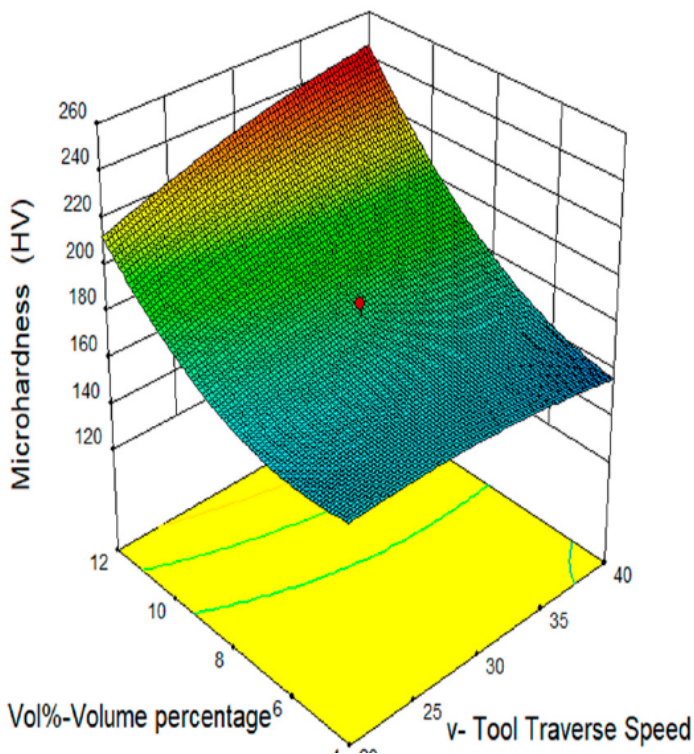

a)

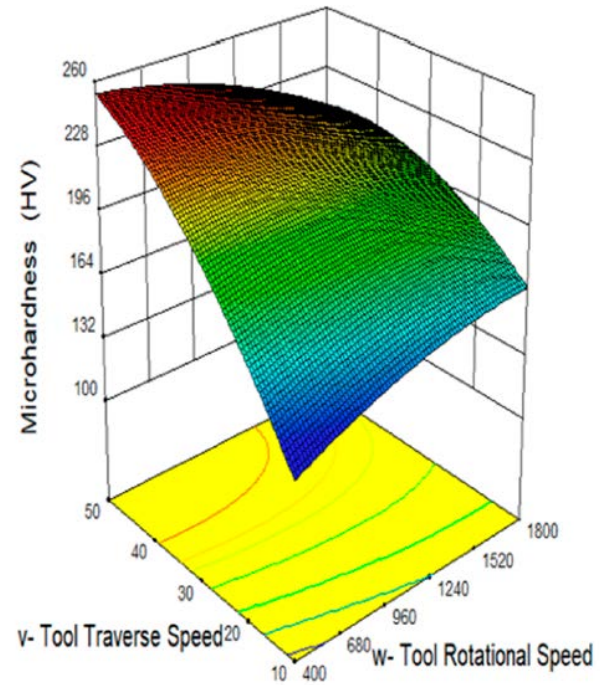

b)

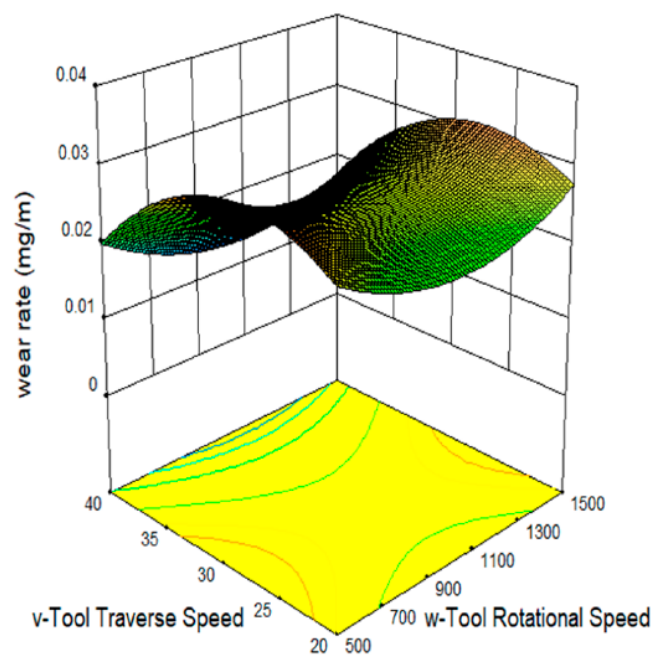

c)

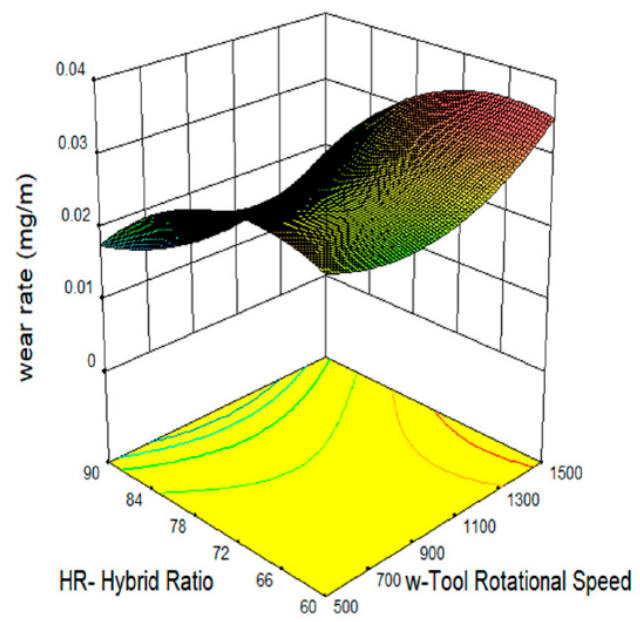

d)

Fig. 9. Effects of tool rotational speed, traverse speed and hybrid ratio on the wear rate and microhardness of AA7075-SiC/fly ash composites: a), b), c), d [13] 
The degree of uniformity of distribution of $\mathrm{SiC}$ reinforcing particles mixed with industrial powder in the base alloy AA7075 is most important for improving the microhardness and wear resistance of composites.

The minimum wear rate is achieved in the sample processed with combination of parameters $\mathrm{w}=1000 \mathrm{rpm}$, $\mathrm{v}=40 \mathrm{~mm} / \mathrm{min}, \mathrm{HR}=75: 25$, concentration 8 vol. \%; and the maximum hardness of 241,2 HV is achieved in the sample processed with combination of parameters $\mathrm{w}=500 \mathrm{rpm}$, $\mathrm{v}=40 \mathrm{~mm} / \mathrm{min}, \mathrm{HR}=90: 10$, concentration $12 \mathrm{vol} . \%$.

\section{OVERLAPPING FSW OF ALUMINUM ALLOY AA6061 WITH INTERMEDIATE GRAPHENE LAYER}

The main disadvantage of aluminum based MMCs is the poor weldability when applying conventional fusion welding technologies [14], [15]. The defects observed are inclusions, porosity, chemical interaction between the materials of reinforcement and matrix, high residual stresses and cracking due to the substantial difference between the coefficients of thermal expansion of matrix material and reinforcement [16], [17]. Their presence reduces the weld efficiency up to $50 \%$ than that of the base material [18]. Another substantial reason for the reduced efficiency in fusion welding of MMCs are the metallurgical aspects, such as the increase of grain size up to 10 times compared to the base material, along with the large heat affected zone (HAZ) [19]. These problems can be effectively overcome by the method of friction stir welding (FSW).

Over the last decade, graphene has been developed as a promising reinforcement for various aluminum-based composites. Its low density and exceptional mechanical and thermal properties make it ideal reinforcement in various low density alloys [20]. The large surface of the graphene sheets favours its strong interfacial connection with the metal phase of the composite. In solid state preparation of Al-graphene composite by FSW, a huge decrease in the degree of wear is also observed [21]. In another study conducted by Jeon et al. [22] the thermal conductivity of a graphene-reinforced composite is increased by near $15 \%$ when obtained by FSW. Khodabakhshi et al. [23] also observe a near 50\% increase in hardness and a threefold increase in strength of graphene-containing aluminum as reinforcement.

Despite graphene is efficient enough to substantially increase the strength of the alloy or composite, its implementation is limited by its lower corrosion resistance in aluminum alloys, since graphene layers activate the corrosion of aluminum due to occurrence of galvanic corrosion [24].

The study reported in [25] shows the increase of strength of aluminum alloys welded by FSW with overlapping (Fig. 10), using an intermediate layer of graphene nanoplatelets (GNP) in the interface of the weld joint.

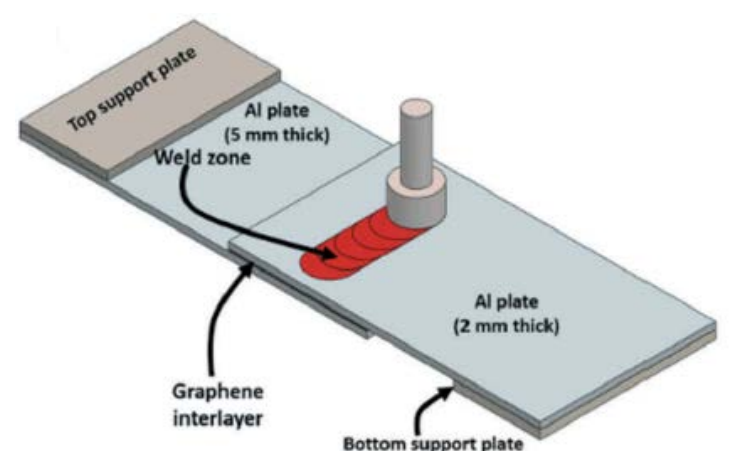

Fig. 10. Schematic representation of FSW [25].

The study shows that when using GNP as an intermediate layer, the strength of the welded joint increase by $121 \%$ and the percentage elongation increases by $53 \%$ compared to the weld without an intermediate layer. In the case of an intermediate layer weld, the bottom of the top plate on the retreating side acts as a potential fracture site due to the presence of an interfacial defect and an undeformed GNP layer. The strengthening of the weld is due to various primary reinforcement mechanisms such as thermal discrepancy, grain refinement, Orowan mechanism, and load transfer.

The following advantages are also observed when using an intermediate layer of GNP:

- $\quad$ the type of destruction changes from brittle to plastic; - the grain size in the welding zone decreases by 38\%;

- the height of the Hook Defect HD (CD) and the cold lap defect CLD decreased by $26 \%$ and $41 \%$ respectively;

- $\quad$ preventing the formation of a layer of $\mathrm{Al} 2 \mathrm{O} 3$ on the surface of the overlap and thus contributing to a significant strengthening of the welded joint.

The technique of FSW of aluminum alloys with overlapping and GNP can also be used to obtain hybrid metal matrix composites.

\section{Acknowledgements}

The authors thank the Bulgarian Scientific Research Fund for funding according to the contract KP-06-India/10, as well as Prof. Adepu Kumar and Dr. Krishna Kishore for sharing some of their work ideas and articles.

\section{REFERENCES}

[1] M. J. Jweed, A. M. Takhakh, N. K. Kareem, “Comparison between Friction stir welding (FSW) and Friction stir processing (FSP) of AA5086 aluminum alloy”, International Journal of Technical Research and Applications, Volume 3, Issue 6 (NovemberDecember,2015), pp 205-210.

[2] R.S. Mishra, M.W. Mahoney, S.X. McFadden, N.A. Mara, A.K. Mukherjee, Scripta Mater. 42 (2000) 163

[3] R.S. Mishra, M.W. Mahoney, Mater. Sci. Forum 357-359 (2001) 507

[4] W.M. Thomas, E.D. Nicholas, J.C. Needham, M.G. Murch, P. Templesmith, C.J. Dawes, G.B. Patent Application No. 9125978.8 (December 1991). 
[5] Z.Y. Ma, R.S. Mishra, M.W. Mahoney, Acta Mater. 50 (2002) 4419

[6] R. Kapoor, N. Kumar, R.S. Mishra, C.S. Huskamp, K.K. Sankaran, "Influence of fraction of high angle boundaries on the mechanical behavior of an ultrafinegrained Al-Mg alloy”. Mater. Sci. Eng., 2010 A 527, 5246-5254, http://dx.doi.org/10.1016/j.msea.2010.04.086

[7] P. Naresh, A. Kumar "Effect of Nano Reinforcement On Fabrication of $\mathrm{Al} / \mathrm{Al} 2 \mathrm{O} 3$ Surface Composite By Friction Stir Processing”, Materials Science forum, Vols. 830-831, pp 467-471

[8] R.S. Mishra, Z.Y. Ma / Materials Science and Engineering R 50 (2005) 1-78

[9] W.M. Thomas, K.I. Johnson, C.S. Wiesner, Adv. Eng. Mater. 5 (2003) 485.

[10] W.M. Thomas, E.D. Nicholas, S.D. Smith, in: S.K. Das, J.G. Kaufman, T.J. Lienert (Eds.), „Aluminum 2001-Proceedings of the TMS 2001 Aluminum Automotive and Joining Sessions,“ TMS, 2001, p. 213.

[11] A. Kumar, K.K. Mugada "Effect of knurling shoulder design with polygonal pins on material flow and mechanical properties during friction stir welding of $\mathrm{Al}-\mathrm{Mg}-\mathrm{Si}$ alloy” Trans. Nonferrous Met. Soc. China 29(2019) 2281-2289

[12] A. M. Hassan, T. Qasim, and A. Ghaithan, "Effect of Pin Profile on Friction Stir Welded Aluminum Matrix Composites”, Materials and Manufacturing Processes, 2012, 27: 1397-1401,

[13] P. A. Namdev, R. P. Srinivasa, O. B. Mamat and A. M. Lubis, Effect of SiC/Fly Ash Reinforcement on Surface Properties of Aluminum 7075 Hybrid Composites, Coatings, June 2020, 10, 541, doi:10.3390.

[14] B. Sahoo, S. D. Girhe, J. Paul, "Influence of process parameters and temperature on the solid state fabrication of multilayered graphenealuminium surface nanocomposites”. J. Manuf. Process. 2018, 34, 486-494

[15] B. Sahoo, D. Narsimhachary, J. Paul, "Tribological behavior of solid-state processed Al-1100/GNP surface nanocomposites”. J. Mater. Eng. Perform. 2018, 27, 6529-6544. DOI: 10.1007/s11665018-3727-6.

[16] V. K. Parikh, A. D. Badgujar, N. D. Ghetiya, "Joining of metal matrix composites using friction stir welding: a review”, Mater. Manuf. Process. 2019, 34, 123-146. DOI: 10.1080/10426914.2018.1532094.
[17] T. Prater, "Solid-state joining of metal matrix composites: a survey of challenges and potential solutions.”, Mater. Manuf. Process 2011, 26, 636-648. DOI: 10.1080/10426914. 2010.492055.

[18] T. K. Pal, “Joining of aluminium metal matrix composites”. Mater. Manuf. Process. 2005, 20, 717-726. DOI: 10.1081/AMP200055116.

[19] A. Sharma, V. M.Sharma, B. Sahoo, S. K. Pal, J. Paul, "Effect of multiple micro channel reinforcement filling strategy on Al6061graphene nanocomposite fabricated through friction stir processing”, J. Manuf. Process. 2019, 37, 53-70. DOI: 10.1016/j. jmapro.2018.11.009.

[20] R. Maurya, B. Kumar, S. Ariharan, J. Ramkumar, K. Balani, "Effect of carbonaceous reinforcements on the mechanical and tribological properties of friction stir processed Al6061 alloy", Mater. Des. 2016, 98, 155-166. DOI: 10.1016/j.matdes.2016.03.021.

[21] J. B. Fernandez, E. J. Macias, J. S. Muro, L. Caputi, D. Miriello, R. De Luca, A. S. Roca, H. C. Fals, "Tribological behavior of AA1050H24-graphene nanocomposite obtained by friction stir processing”, Metals (Basel). 2018, 8, $113 . \quad$ DOI: 10.3390/met8020113.

[22] C. H. Jeon, Y. H. Jeong, J. J. Seo, H. N. Tien, S.T. Hong, Y. J. Yum, S. H. Hur, K. J. Lee, "Material properties of graphene/aluminum metal matrix composites fabricated by friction stir processing”, Int. J. Precis. Eng. Manuf. 2014, 15, 1235-1239. DOI: 10.1007/s12541014-0462-2.

[23] F. Khodabakhshi, M. Nosko, A. P. Gerlich, "Effects of graphene nano-platelets (Gnps) on the microstructural characteristics and textural development of an Al-Mg alloy during friction-stir processing”, Surf. Coatings Technol. 2018, 335, 288-305. DOI: 10.1016/j.surfcoat.2017.12.045.

[24] F. H. Latief, E. S. Sherif, A. A. Almajid, H. Junaedi, "Fabrication of exfoliated graphite nanoplatelets-reinforced aluminum composites and evaluating their mechanical properties and corrosion behavior”, J. Anal. Appl. Pyrolysis. 2011, 92, 485-492. DOI: 10.1016/j.jaap.2011.09.003.

[25] A. Sharma, V. Sharma, A. Gugaliy, P. Rai, S. K. Pal, and J, Paul, Friction stir lap welding of AA6061 aluminium alloy with a graphene interlayer”, Materials and Manufacturing Processes, January 2020

DOI: 10.1080/10426914.2020.1718694. 